\title{
Influence of adjacent surface building on seismic response of shallow buried subway station structure
}

\author{
Wenliang Huang1, Tao Liu' ${ }^{2}$, Yan Ge ${ }^{3}$, Han Wang ${ }^{4}$, Liangjian Zhong ${ }^{5}$, Xiaoguang Jin ${ }^{6}$ \\ ${ }^{1,2,4,5}$ China Construction Traffic Construction Group Co., Ltd., Sichuan Branch, Chengdu, 610000, China \\ ${ }^{3,6}$ College of Civil Engineering, Chongqing University, Chongqing, 400045, China \\ ${ }^{6}$ Corresponding author \\ E-mail:1813575427@qq.com, ${ }^{2} 107452551 @ q q . c o m,{ }^{3} 634232576 @ q q . c o m,{ }^{4985877445 @ q q . c o m, ~}$ \\ 5154026474@qq.com,6jinxiaoguang@cqu.edu.cn
}

Received 4 January 2019; received in revised form 1 July 2019; accepted 8 July 2019 DOI https://doi.org/10.21595/jve.2019.20502

Check for updates

Copyright $(2020$ Wenliang Huang, et al. This is an open access article distributed under the Creative Commons Attribution License, which permits unrestricted use, distribution, and reproduction in any medium, provided the original work is properly cited.

\begin{abstract}
Taking the 6-storey frame structure as an example, using FLAC numerical simulation, the influence of the adjacent multi-storey buildings on the seismic response of the metro station structure (including the internal force and bias state of the station structure) is studied systematically, and the relationship between the influence and surrounding rock level change is analyzed. The research shows that the existence of surface buildings has obvious amplification effect on the internal force of the subway station and above. It mainly shows that the eccentricity of the vault of the subway station is increased, and the eccentricity of the arch waist is reduced. It has a great influence on the internal force and distribution range of the station structure. The worse the surrounding rock, the greater the internal force and influence range of the building to the station structure.
\end{abstract}

Keywords: surface building, shallow buried subway station, seismic response, structural internal force, surrounding rock.

\section{Introduction}

The appearance and development of subway has greatly improved the urban traffic conditions. The interaction between metro stations and overlying buildings has received more and more attention. Especially in the case of earthquakes, due to the existence of underground space (such as subway stations), subway stations and their structural interfaces have a great influence on the propagation characteristics of seismic waves. At the same time, the surface buildings amplify the waves that are close to their own frequencies in the seismic waves, so that the building foundation generates a reaction force corresponding to its own inertial force, which has a certain influence on the ground motion of the building site, so that the seismic response of the subway station changes.

Some scholars have studied the interaction between underground structures and buildings under earthquake conditions. Liang Jianwen et al. [1-3] used theoretical analysis and numerical simulation to study the influence of seismic waves on ground motion under the condition of underground caverns. It is believed that the amplification effect of underground caverns on ground motion can reach 1.5-8.8 times of the non-cavity. Yu Pinqing [4] studied the seismic response of metro stations on weak foundations and the changes of station-site seismic effects, and analyzed the impact of subway station construction on surface displacement and horizontal velocity. He Wei et al. [5] used FLAC to analyze the changes of surface acceleration and response spectrum of the subway tunnel before and after construction. Fu Yuyong et al. [6] used dynamic finite element method to study the seismic response of layered tunnels to adjacent buildings, and revealed the influence of tunnel depth, building and tunnel spacing on seismic response. Ganainy et al. [7] used numerical simulation to study the seismic response of the multi-storey building basement (or garage) to the superstructure. The stiffness of the foundation soil and the height of the underground space have a great influence on the propagation of seismic waves. He Wei [8] developed the Davidenko viscoelastic constitutive model based on the ABAQUS software, and studied the influence of the subway station on the seismic response of the adjacent frame structure. It is 
considered that the subway station can enlarge the relative displacement of the floor and the shear force of the frame column by $30 \%$ and more than $20 \%$ respectively. Based on the generalized interlayer displacement spectrum, Guo Jing [9] analyzed the influence of metro station on the seismic response of adjacent buildings from the aspects of foundation stiffness, seismic acceleration peak and surface deformation characteristics. Li Fangjie et al. [10] used ANSYS to establish a soil-structure dynamic interaction model, studied the influence of buildings with different relative positions on the seismic response of underground structures, and found the existence of buildings has a great impact on the relative displacement of the subway stations, the internal forces of the nodes, etc. Kyriazis Pitilakis et al. [11] studied the influence of buildings at different locations or at the same location above the tunnel on the seismic response of tunnels. It is considered that when the tunnel has a shallow depth and the tunnel lining stiffness is large, the seismic response of the overlying buildings to the tunnel is considered. The amplification is more significant. Lv Zhitao [12] used theoretical analysis and numerical simulation to study the seismic response characteristics of metro stations and their overlying buildings, and revealed the interaction law between metro stations and overlying buildings under earthquake conditions.

It can be seen from the related research of the above scholars that the research on the seismic response of shallow-buried subway stations is still relatively rare at present. And this paper is focused on the dynamic response of the shallow-buried subway station under earthquake.

In view of this, this paper takes the 6-storey frame structure as an example, and uses the numerical simulation method to systematically study the influence of the adjacent multi-storey buildings on the seismic response of the station structure (including the internal force and bias state of the station structure).

\section{Establishment of dynamic analysis model}

Taking the typical underground excavation station of the first phase of Chongqing Rail Transit Line 9 as the research object, the analysis model is established. The net width of the station is $23.24 \mathrm{~m}$, the net height is $19.92 \mathrm{~m}$, the thickness of the secondary lining C40 is $0.80 \mathrm{~m}$, and the reserved deformation is $120 \mathrm{~mm}$; the surrounding rock classification of the station is Grade IV; the station hall layer is beam-slab structure, the main beam direction is arranged along the longitudinal direction of the station, the width is $1.0 \mathrm{~m}$ and the height is $1.2 \mathrm{~m}$; the secondary beam is arranged along the station transverse direction, the width is $0.80 \mathrm{~m}$, the height is $0.50 \mathrm{~m}$; the thickness of the slab is $0.50 \mathrm{~m}$, A square column is arranged under the main beam, and the column section length is $0.80 \mathrm{~m}$ and the column spacing is $8.40 \mathrm{~m}$.

Taking the 6-storey and 3-span frame structure of the building over the station as an example. The subway station has a depth of $5.00 \mathrm{~m}$, the overlying (directly above) building span is $9.00 \mathrm{~m}$, the bottom layer is $4.00 \mathrm{~m}$ high, the other layers are $3.50 \mathrm{~m}$ high, the beam section is $0.40 \mathrm{~m} \times 0.60 \mathrm{~m}$, and the column section is $0.60 \mathrm{~m} \times 0.60 \mathrm{~m}$. The basic form of the building is an independent foundation under the column. The established dynamic analysis model is shown in Fig. 1. The lower boundary of the model is taken down from the bottom of the station by $30.0 \mathrm{~m}$, the left boundary is taken from the left side wall of the station to the left by $50.0 \mathrm{~m}$, and the right boundary is taken from the right side wall of the station to the right by $65.0 \mathrm{~m}$ and the longitudinal direction is taken as $2.0 \mathrm{~m}$. It's handled as the plane strain problem and the effect of the platform layer is ignored.

In the model, the secondary lining adopts the Shell unit, the station hall beam and the column adopt the Beam unit, the surrounding rock adopts the elastoplastic (M-C) model, and the structure adopts the linear elastic model (Fig. 2). The connection between the column and the station hall beam and the inverted arch of the secondary lining is considered as a rigid connection, and a line load of $30 \mathrm{kN} / \mathrm{m}$ is applied to the beam. In order to carry out the comparative study of different surrounding rock grades, the surrounding rock of Grade III and V is taken as the average value of the corresponding level parameters according to the design specification of the railway tunnel. The parameters of the surrounding rock and the structure (including beam and column) are listed in Table 1. 


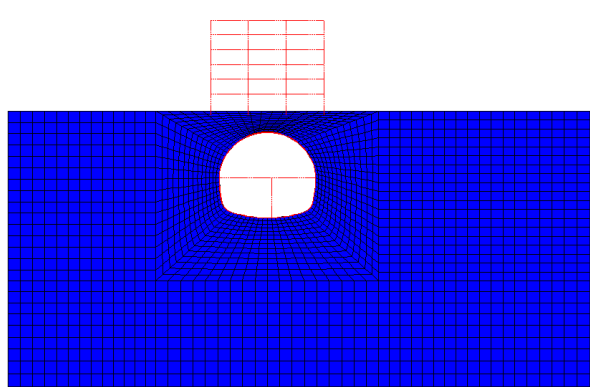

Fig. 1. Dynamic analysis model

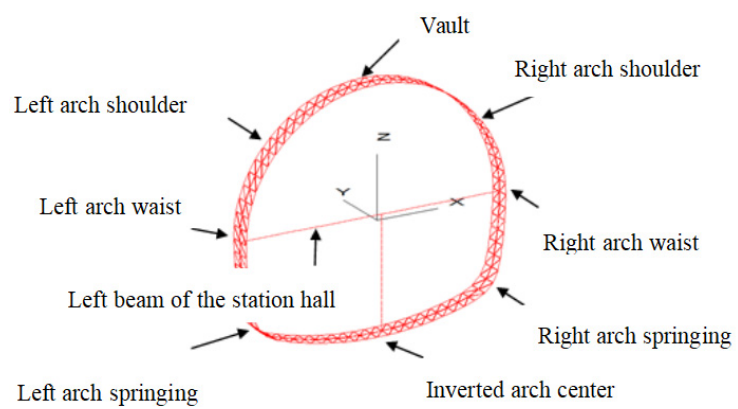

Fig. 2. Station structure model

Table 1. Surrounding rock and structural physical and mechanical parameters

\begin{tabular}{|c|c|c|c|c|c|}
\hline Parameter & $\begin{array}{c}\text { Elastic modulus } \\
E / \mathrm{MPa}\end{array}$ & $\begin{array}{c}\text { Poisson's } \\
\text { ratio } \mu\end{array}$ & $\begin{array}{c}\text { Gravity } \\
\mathrm{kN} / \mathrm{m}^{3}\end{array}$ & $\begin{array}{c}\text { Cohesion } \\
c / \mathrm{kPa}\end{array}$ & $\begin{array}{c}\text { Internal friction } \\
\text { Angle } \varphi /{ }^{\circ}\end{array}$ \\
\hline Grade IV & 1500 & 0.35 & 23.0 & 300 & 33 \\
\hline Grade III & 6000 & 0.25 & 25.0 & 700 & 40 \\
\hline Grade V & 800 & 0.40 & 20.0 & 150 & 25 \\
\hline Station structure & 30000 & 0.20 & 24.0 & - & - \\
\hline
\end{tabular}

In the dynamic analysis, the boundary conditions use the free field boundary provided by FLAC3D. Referring to the references [8, 11-12], taking the damping ratio of the surrounding rock of the metro station to 0.05 , the damping ratio of the station structure to the building is 0.02 . The seismic wave is input horizontally from the bedrock surface. The seismic wave adopts the intercepted Kobe wave and is corrected and filtered by the SeismoSignal software. The acceleration time history and Fourier spectrum characteristics are shown in Fig. 3. The acceleration peak value is $0.15 \mathrm{~g}$.

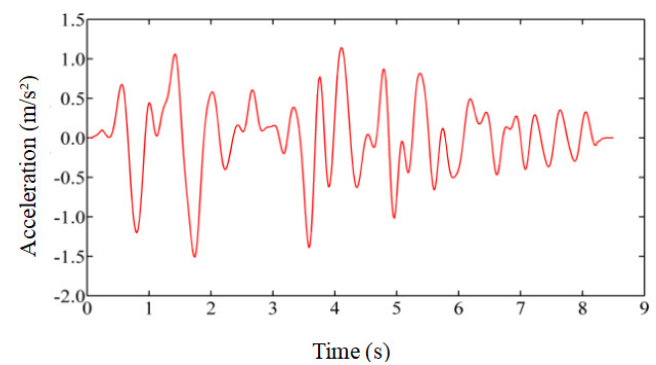

a) Acceleration time history

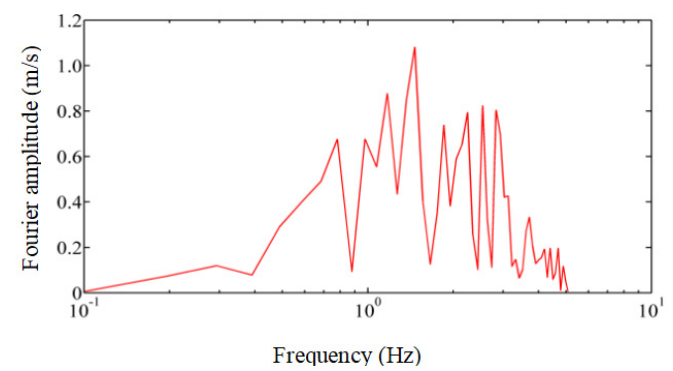

b) Fourier spectrum

Fig. 3. Selected seismic wave characteristics

\section{Internal force analysis of metro station structure}

Fig. 4 to Fig. 5 are the time-history curves of the arch bending moment and axial force of the metro station at the time of earthquake and earthquake. Table 2 shows the peak value of the dynamic internal force of each typical position of the metro station structure with or without buildings under earthquake action.

It can be seen from Fig. 4 to Fig. 5 and Table 2 that the existence of the surface buildings has a great influence on the internal forces of the station vault and the arch waist, and the influence on the internal forces of the arch springing, the inverted arch, the station floor and the column is not obvious, that is, the impact of surface buildings on the seismic response of metro stations is mainly above the station hall level. The existence of surface buildings increased the peak value of the vault bending moment of the metro station by $41.0 \%$, the average level of the dynamic bending moment increased from $200 \mathrm{kN} \cdot \mathrm{m} / \mathrm{m}$ to $400 \mathrm{kN} \cdot \mathrm{m} / \mathrm{m}$; the peak value of the axial force increased 
by $5.8 \%$. The average level of the dynamic axial force increased from $-700 \mathrm{kN} / \mathrm{m}$ to $-950 \mathrm{kN} / \mathrm{m}$. The influence of surface construction on the bending moment at the station vault is much more significant than that of the axial force, and the influence on the peak value of the bending moment is 7.10 times that of the influence on the peak value of the axial force.

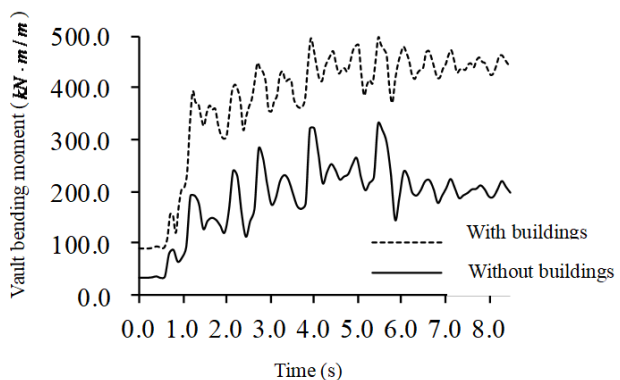

Fig. 4. Time history curve of bending moment of metro station vault

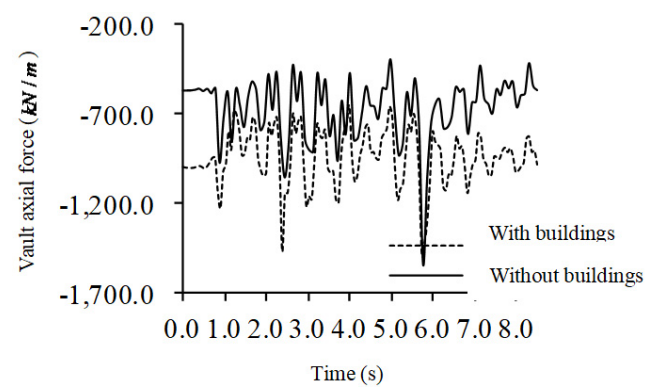

Fig. 5. Time history curve of axial force of metro station vault

Fig. 6 to Fig. 7 are the time curves of the bending moment and the axial force of the right arch waist of the metro station when there is no construction under earthquake.

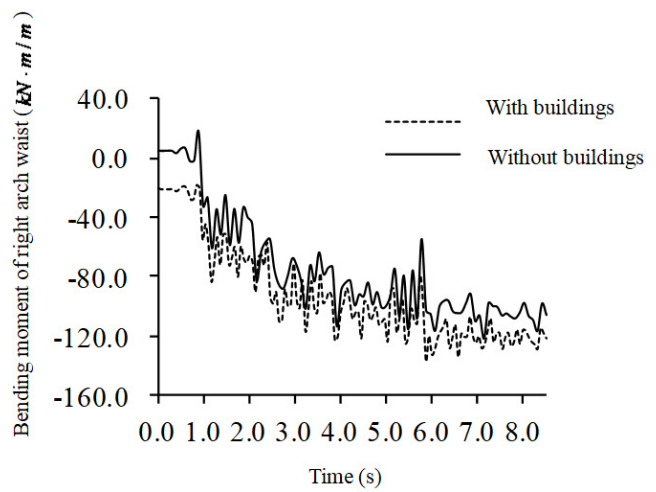

Fig. 6. Time history curve of bending moment of right arch waist of metro station

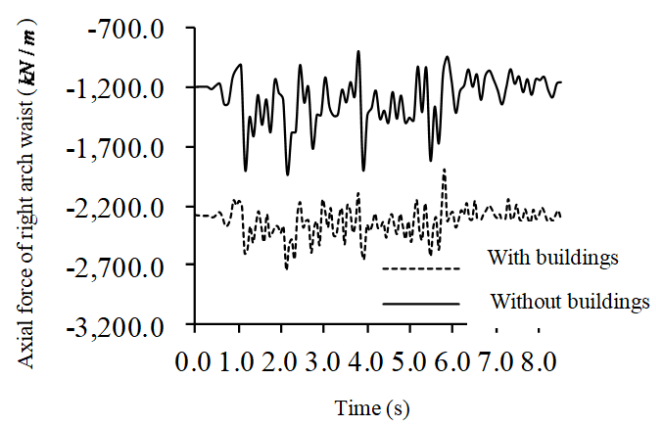

Fig. 7. Time history curve of right arch waist of metro station

It can be seen from Fig. 6 to Fig. 7 and Table 2 that the presence of surface buildings increases the peak bending moment of the right arch waist of the metro station by $11.2 \%$, and the average level of the dynamic bending moment increases from $80 \mathrm{kN} \cdot \mathrm{m} / \mathrm{m}$ to $100 \mathrm{kN} \cdot \mathrm{m} / \mathrm{m}$; the axial force peak increased by $36.0 \%$, and the average horizontal force increased from $-1400 \mathrm{kN} / \mathrm{m}$ to $-2400 \mathrm{kN} / \mathrm{m}$. The influence on the peak force of the arch waist is 3.2 times that of the peak of the bending moment. The left arch waist also exhibits the same characteristics as the right arch waist. Therefore, the influence of surface buildings on the axial force of the arch waist of the metro station is much larger than the bending moment. This is contrary to the influence of the surface buildings on the vault of the subway station under the action of earthquakes. 
Table 2. Peak internal force of subway station structure in earthquake

\begin{tabular}{|c|c|c|c|c|}
\hline \multirow{2}{*}{ Part of the station } & Internal force name & $\begin{array}{c}\text { Without } \\
\text { buildings }\end{array}$ & $\begin{array}{c}\text { With } \\
\text { buildings }\end{array}$ & Influence level \\
\hline \multirow{2}{*}{ Vault } & Bending moment $(\mathrm{kN} \cdot \mathrm{m} / \mathrm{m})$ & 351 & 495 & Increased by $41.0 \%$ \\
\cline { 2 - 5 } & Axial force $(\mathrm{kN} / \mathrm{m})$ & -1632 & -1726 & Increased by $5.8 \%$ \\
\hline \multirow{2}{*}{ Right arch shoulder } & Bending moment $(\mathrm{kN} \cdot \mathrm{m} / \mathrm{m})$ & -226.5 & -325.2 & Increased by $44.0 \%$ \\
\cline { 2 - 5 } & Axial force $(\mathrm{kN} / \mathrm{m})$ & -3700 & -4550 & Increased by $23.0 \%$ \\
\hline \multirow{2}{*}{ Left arch shoulder } & Bending moment $(\mathrm{kN} \cdot \mathrm{m} / \mathrm{m})$ & -242 & -297 & Increased by $23.0 \%$ \\
\cline { 2 - 5 } & Axial force $(\mathrm{kN} / \mathrm{m})$ & -3460 & -3890 & Increased by $12.4 \%$ \\
\hline \multirow{2}{*}{ Right arch waist } & Bending moment $(\mathrm{kN} \cdot \mathrm{m} / \mathrm{m})$ & -125 & -139 & Increased by $11.2 \%$ \\
\cline { 2 - 5 } & Axial force $(\mathrm{kN} / \mathrm{m})$ & -2030 & -2750 & Increased by $36.0 \%$ \\
\hline \multirow{2}{*}{ Left arch waist } & Bending moment $(\mathrm{kN} \cdot \mathrm{m} / \mathrm{m})$ & -174 & -149 & Decreased by $14.4 \%$ \\
\cline { 2 - 5 } & Axial force $(\mathrm{kN} / \mathrm{m})$ & -2040 & -2650 & Increased by $30.0 \%$ \\
\hline \multirow{2}{*}{ Right arch springing } & Bending moment $(\mathrm{kN} \cdot \mathrm{m} / \mathrm{m})$ & -744 & -768 & Changed by $3.2 \%$ \\
\cline { 2 - 5 } & Axial force $(\mathrm{kN} / \mathrm{m})$ & -4680 & -4920 & Changed by $5.2 \%$ \\
\hline \multirow{2}{*}{$\begin{array}{c}\text { Left arch springing } \\
\text { Inverted arch center }\end{array}$} & Bending moment $(\mathrm{kN} \cdot \mathrm{m} / \mathrm{m})$ & -1058 & -1071 & Changed by $1.2 \%$ \\
\cline { 2 - 5 } & Axial force $(\mathrm{kN} / \mathrm{m})$ & -5629 & -5648 & Changed by $0.3 \%$ \\
\cline { 2 - 5 } & Bending moment $(\mathrm{kN} \cdot \mathrm{m} / \mathrm{m})$ & 491 & 533 & Increased by $8.5 \%$ \\
\hline \multirow{2}{*}{$\begin{array}{c}\text { Right end of left beam } \\
\text { in station hall }\end{array}$} & Axial force $(\mathrm{kN} / \mathrm{m})$ & -1284 & -1235 & Changed by $3.8 \%$ \\
\cline { 2 - 5 } & Bending moment $(\mathrm{kN} \cdot \mathrm{m})$ & 264 & 267 & Changed by $1.1 \%$ \\
\cline { 2 - 5 } & Axial force $(\mathrm{kN})$ & 3700 & 3520 & Changed by $4.9 \%$ \\
\cline { 2 - 5 } & Shearing force $(\mathrm{kN})$ & 97 & 99 & Changed by $2.1 \%$ \\
\hline
\end{tabular}

\section{Structural bias analysis of metro station}

From the analysis results, the bending moment value and the axial force value of the structure of the same position of the subway station are extracted, and the ratio of the two is the time-history curve of the eccentricity. The influence of surface buildings on the bending moment of the station vault is much more significant than that to the axial force, and the influence on the axial force of the arch waist is much greater than that on the bending moment.

Fig. 8 to Fig. 9 show the eccentricity time-history curves of the metro station vault and the right arch waist when there are no surface buildings.

It can be seen that the existence of the surface building increases the eccentricity of the vault of the subway station and the eccentricity of the arch waist decreases. Analyzing the force mechanism, the arch structure above the metro station platform can be regarded as arched beam, the arch waist is regarded as the fixed support of the beam, the surface building is regarded as the vertical load, and the vertical load on the middle of the beam span significantly increases the bending moment at the middle of the beam, but has less influence on the axial force at the middle of the beam, and meanwhile has a greater influence on the axial force of the support, but less influence on the bending moment.

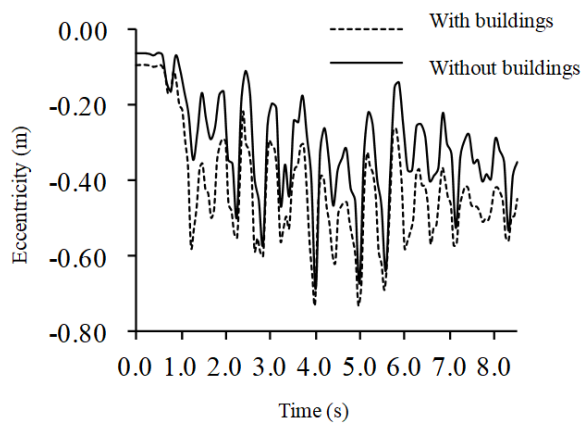

Fig. 8. Time-history curve of eccentricity of metro station vault

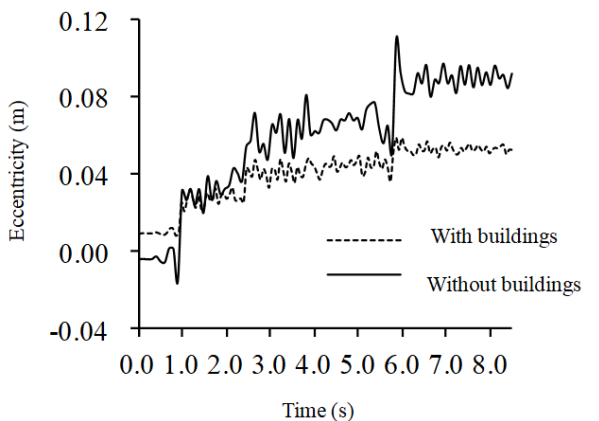

Fig. 9. Time-history curve of eccentricity of right arch waist in metro station 


\section{Influence of surrounding rock classification}

In order to study the influence of surface buildings on the seismic response of metro stations under different surrounding rock conditions, the seismic response of the Grade III and V surrounding rock conditions is also analyzed, and compared with the results of the Grade IV surrounding rock analysis.

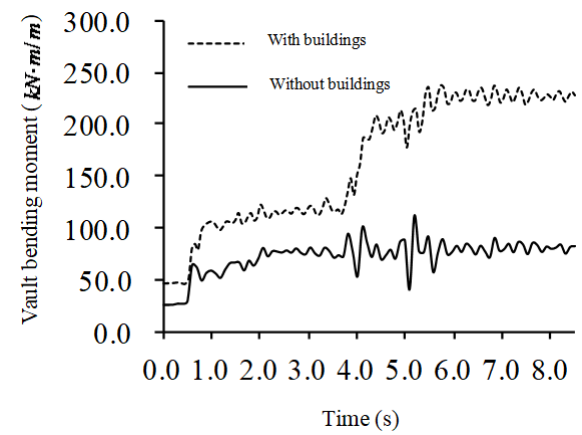

Fig. 10. Time-history curve of crown moment of station in Grade III surrounding rock

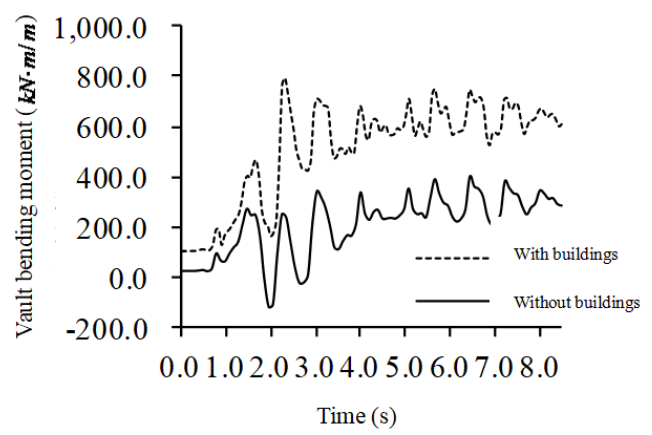

Fig. 12. Time-history curve of bending moment at the crown of station in Grade V surrounding rock

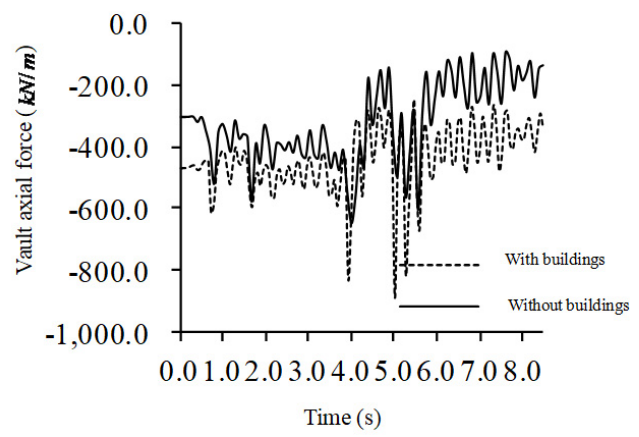

Fig. 11. Time-history curve of the axial force at the crown of station in Grade III surrounding rock

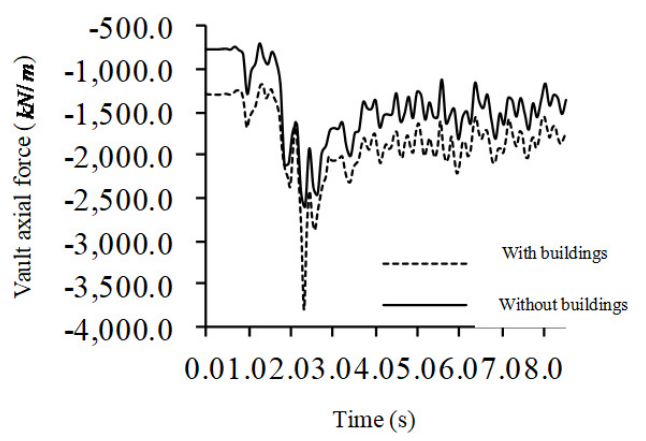

Fig. 13. Time-history curve of the axial force at the crown of station in Grade V surrounding rock

Figs. 10-13 are the time-history curves of the vault bending moment and axial force of the metro station at the conditions of the III and V surrounding rock with and without the surface buildings. Table 3 shows the comparison of the internal force peak of typical positions of metro stations with and without surface structures under different surrounding rock conditions.

Comparing and analyzing of Fig. 4, Fig. 5, Figs. 10-13, and Table 3, it can be seen that:

1) Whether the surface building exists or not, as the surrounding rock level decreases, the internal force of the station structure gradually decreases. Taking the vault axial force of the metro station as an example, under the conditions of surrounding rock of Grade V, Grade IV and Grade III, the values are $-2669 \mathrm{kN} / \mathrm{m},-1632 \mathrm{kN} / \mathrm{m}$ and $-858 \mathrm{kN} / \mathrm{m}$ respectively without surface buildings. The values are $-3814 \mathrm{kN} / \mathrm{m},-1726 \mathrm{kN} / \mathrm{m}$ and $-894 \mathrm{kN} / \mathrm{m}$ respectively with surface buildings, and the axial force all decreases with the decrease of surrounding rock grade.

2) The smaller the surrounding rock grade, that is, the better the surrounding rock, the smaller the influence range of the surface building on the station structure. Under the conditions of surrounding rock at all levels, the influence of surface buildings is mainly reflected in the above area of the station hall.

3) Under the condition of Grade V surrounding rock, the surface construction not only has a great influence on the internal forces of the station vault and the arch waist, but also has a significant influence on the internal forces of the arch springing, the inverted arch and the beams 
of the station hall, that is, under the condition of Grade V surrounding rock, the influence of the adjacent surface buildings has reached the entire station structure.

Table 3. Comparison of peak internal force of station structure

\begin{tabular}{|c|c|c|c|c|}
\hline Compared Items & $\begin{array}{c}\text { Surrounding } \\
\text { rock grade }\end{array}$ & $\begin{array}{c}\text { With } \\
\text { buildings }\end{array}$ & $\begin{array}{c}\text { Without } \\
\text { buildings }\end{array}$ & Influence level \\
\hline \multirow{3}{*}{$\begin{array}{l}\text { Vault bending moment } \\
\qquad(\mathrm{kN} \cdot \mathrm{m} / \mathrm{m})\end{array}$} & III & 241 & 128 & Increased by $88.3 \%$ \\
\hline & IV & 495 & 351 & Increased by $40.9 \%$ \\
\hline & $\mathrm{V}$ & 807 & 402 & Increased by $100.7 \%$ \\
\hline \multirow{3}{*}{ Vault axial force $(\mathrm{kN} / \mathrm{m})$} & III & -894 & -858 & Increased by $4.2 \%$ \\
\hline & IV & -1726 & -1632 & Increased by $5.7 \%$ \\
\hline & $\mathrm{V}$ & -3814 & -2669 & Increased by $42.9 \%$ \\
\hline \multirow{3}{*}{$\begin{array}{l}\text { Bending moment } \\
\text { of right } \operatorname{arch} \text { shoulder }(\mathrm{kN} \cdot \mathrm{m} / \mathrm{m})\end{array}$} & III & -101 & -74 & Increased by $36.5 \%$ \\
\hline & IV & -325 & -226 & Increased by $43.8 \%$ \\
\hline & $\mathrm{V}$ & -523 & -406 & Increased by $28.8 \%$ \\
\hline \multirow{3}{*}{$\begin{array}{l}\text { Axial force of right } \\
\text { arch shoulder }(\mathrm{kN} / \mathrm{m})\end{array}$} & III & -3134 & -2554 & Increased by $22.7 \%$ \\
\hline & IV & -4550 & -3700 & Increased by $22.9 \%$ \\
\hline & $\mathrm{V}$ & -5041 & -3825 & Increased by $31.8 \%$ \\
\hline \multirow{3}{*}{$\begin{array}{l}\text { Bending moment of right } \\
\text { arch waist }(\mathrm{kN} \cdot \mathrm{m} / \mathrm{m})\end{array}$} & III & -104 & -132 & Decreased by $21.2 \%$ \\
\hline & IV & -139 & -125 & Increased by $11.2 \%$ \\
\hline & $\mathrm{V}$ & -165 & 183 & - \\
\hline \multirow{3}{*}{$\begin{array}{c}\text { Axial force } \\
\text { of right arch waist } \\
(\mathrm{kN} / \mathrm{m})\end{array}$} & III & -1950 & -1465 & Increased by $33.1 \%$ \\
\hline & IV & -2750 & -2030 & Increased by $35.5 \%$ \\
\hline & $\mathrm{V}$ & -5094 & -3625 & Increased by $40.5 \%$ \\
\hline \multirow{3}{*}{$\begin{array}{l}\text { Bending moment } \\
\text { of right arch springing } \\
(\mathrm{kN} \cdot \mathrm{m} / \mathrm{m})\end{array}$} & III & -179 & -164 & Increased by $9.1 \%$ \\
\hline & IV & -768 & -744 & Increased by $3.2 \%$ \\
\hline & $\mathrm{V}$ & -1591 & -1696 & Decreased by $6.2 \%$ \\
\hline \multirow{3}{*}{$\begin{array}{l}\text { Axial force of right } \\
\text { arch springing } \\
(\mathrm{kN} / \mathrm{m})\end{array}$} & III & -3958 & -3826 & Increased by $3.5 \%$ \\
\hline & IV & -4920 & -4680 & Increased by $5.1 \%$ \\
\hline & $\mathrm{V}$ & -6853 & -6012 & Increased by $14.0 \%$ \\
\hline \multirow{3}{*}{$\begin{array}{l}\text { Bending moment of inverted } \\
\text { arch center }(\mathrm{kN} \cdot \mathrm{m} / \mathrm{m})\end{array}$} & III & 254 & 241 & Increased by $5.4 \%$ \\
\hline & IV & 533 & 491 & Increased by $8.5 \%$ \\
\hline & $\mathrm{V}$ & 1244 & 1151 & Increased by $8.1 \%$ \\
\hline \multirow{3}{*}{$\begin{array}{l}\text { Axial force of inverted } \\
\text { arch center }(\mathrm{kN} / \mathrm{m})\end{array}$} & III & -844 & -882 & Decreased by $4.3 \%$ \\
\hline & IV & -1235 & -1284 & Decreased by $3.8 \%$ \\
\hline & $\mathrm{V}$ & -3979 & -3307 & Increased by $20.3 \%$ \\
\hline \multirow{3}{*}{$\begin{array}{l}\text { Bending moment of right end } \\
\text { of left beam in station hall } \\
(\mathrm{kN} \cdot \mathrm{m})\end{array}$} & III & 146 & 142 & Changed within $5 \%$ \\
\hline & IV & 267 & 264 & Changed within $5 \%$ \\
\hline & $\mathrm{V}$ & 458 & 473 & Changed within $5 \%$ \\
\hline \multirow{3}{*}{$\begin{array}{l}\text { Axial force of Right end of left } \\
\text { beam in station hall }(\mathrm{kN})\end{array}$} & III & 2322 & 2693 & Decreased by $13.7 \%$ \\
\hline & IV & 3520 & 3700 & Decreased by $4.9 \%$ \\
\hline & $\mathrm{V}$ & 4968 & 1868 & Increased by $166.0 \%$ \\
\hline
\end{tabular}

Wenliang Huang simplified and then established the model by FLAC 3D based on the actual structural form and dimensions of the surface building. Tao Liu conducted an internal force analysis of the dynamic response of the structure under earthquake action and conducted a comparative analysis of the structural internal forces with and without the surface building. Yan referred to the domestic and foreign research dynamics, determined the research method of numerical simulation, and used FLAC 3D to establish the model of the structure. Han Wang conducted the structural bias analysis of the subway station with and without the surface building. Liangjian Zhong conducted the structural bias analysis of the subway station with and without the surface building, made the layout and polished the paper. Xiaoguang Jin analyzed the influence of surrounding rock classification on the structural dynamic response to the earthquake action and drew some conclusions. 


\section{Conclusions}

1) The influence of surface buildings on the internal force of the metro station structure is mainly manifested in range above the station hall floor. The influence of the surface buildings on the bending moment of the station vault is more significant than the axial force, and the influence on the axial force of the arch waist is more significant than that of the bending moment.

2) The presence of the building increases the eccentricity of the station vault and reduces the eccentricity at the arch waist, which is related to the force mechanism of the station structure.

3) The better the surrounding rock, the smaller the internal force of the station structure, and the less obvious the amplifying effect of the surface building on the internal force of the station structure, and the smaller the scope of influence.

4) From the Grade V surrounding rock to the Grade III surrounding rock, the amplification effect of the surface structure on the internal force of the station structure gradually reduces. Taking the station vault bending moment as an example, under the condition of Grade V, Grade IV and Grade III surrounding rock, the amplification coefficients of the internal forces of the surface structures to the station structure are 2.01, 1.88 and 1.41, respectively.

5) In order to improve the seismic performance of subway station, some effective measures were discussed and can be considered during seismic design:

6) Under the action of earthquakes, the presence of surface buildings increases the bending moment and axial force at the vault and the arch waist. According to the results of numerical simulation, the seismic performance of the lining structure can be improved by optimizing the design of the concrete and steel of the lining structure.

7) Similarly, subway stations under poor surrounding rock also need to improve the design requirements for secondary lining, and adopt concrete and steel with higher strength to ensure the safety of the station structure.

\section{Acknowledgements}

This research is funded by the Science and Technology Plan Project "Study on the unloading mechanism and excavation method optimization of surrounding rock of metro station in mountainous city" of China Construction Traffic Construction Group Co., Ltd.

\section{References}

[1] Li Yanheng Influence of Underground Cavern Groups on Ground Motion - SH Wave Incidence. Tianjin University, Tianjin, 2004.

[2] Liang Jianwen, Zhang Hao, Vincent Lee W. Influence of underground cavern groups on ground motion. Rock Mechanics, Vol. 38, Issue 2, 2005, p. 206-223.

[3] Liang Jianwen, Li Yanheng, Vincent Lee W. Series solution to the problem of underground caverns affecting ground motion: SH wave incidence. Rock Mechanics, Vol. 27, Issue 10, 2006, p. 1663-1672.

[4] Yu Pinqing Seismic Response and Environmental Impact Assessment of Underground Structure in Soft Soil. Dalian University of Technology, Dalian, 2009.

[5] He Wei, Chen Jianyu, Yu Pinqing Study on the influence of underground structure development on site surface response spectrum. Journal of Underground Space and Engineering, Vol. 5, Issue 6, 2009, p. 1098-1102.

[6] Fu Yuyong, Run Pengwang, Hu Zixue Influence of subway tunnels on seismic response of adjacent buildings in layered sites. Building Structure, Vol. 39, Issue 11, 2009, p. 46-49.

[7] Ganainy H., Naggar M. H. Seismic performance of three-dimensional frame structures with underground stories. Soil Dynamic and Earthquake Engineering, Vol. 29, 2009, p. 1249-1261.

[8] He Wei Study on Seismic Response of Underground Structures and its Influence on Surface Buildings. Dalian University of Technology, Dalian, 2011.

[9] Guo Jing Study of Dynamic Deformation of Underground Structures and its Influence on Seismic Response of Surface Buildings. Dalian University of Technology, Dalian, 2013. 
[10] Li Fangjie, Zhao Fengxin, Zhang Yushan, et al. Influence of the above-ground structure of the relative position on the seismic response of underground subway structures. China Earthquake, Vol. 26, Issue 2, 2010, p. 201-209.

[11] Kyriazis Pitilakis, Grigorios Tsinidis, Andrea Leanza, et al. Seismic behaviour of circular tunnels accounting for above ground structures interaction effects. Soil Dynamics and Earthquake Engineering, Vol. 67, 2014, p. 1-15.

[12] Lv Zhitao Study on Seismic Response Characteristics of Metro Station and its Overlying Buildings. Chongqing University, Chongqing, 2015.

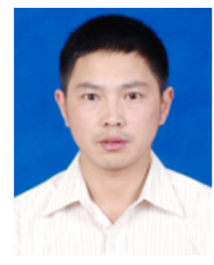

Wenliang Huang received Bachelor's degree, and now works at China Construction Transportation Construction Group Co., Ltd. Sichuan Branch.

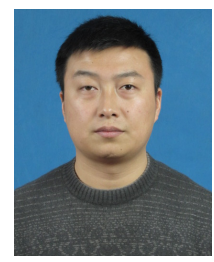

Tao Liu received Bachelor's degree, and now works at China Construction Transportation Construction Group Co., Ltd. He conducted an internal force analysis of the dynamic response of the structure under earthquake action and conducted a comparative analysis of the structural internal forces with and without the surface building.

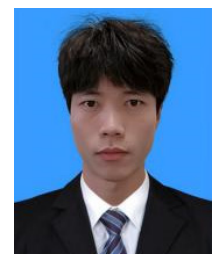

Yan Ge received Bachelor's degree in civil engineering from China University of Mining and Technology in Xuzhou of China in 2017. Now he is studying for Master's degree in Chongqing University in Chongqing, China. His current study area is urban underground space and tunnels. He referred to the domestic and foreign research dynamics, determined the research method of numerical simulation, and used FLAC 3D to establish the model of the structure.

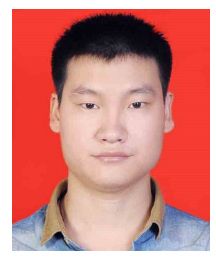

Han Wang received Bachelor's degree, and now he works at China Construction Transportation Construction Group Co., Ltd. He conducted the structural bias analysis of the subway station with and without the surface building.

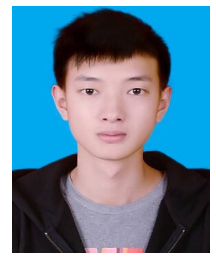

Liangjian Zhong received Bachelor's degree, and now he works at China Construction Transportation Construction Group Co., Ltd. Sichuan Branch. He conducted the structural bias analysis of the subway station with and without the surface building, made the layout and polished the paper.

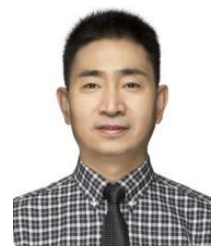

Xiaoguang Jin received Doctor's degree in geological engineering from Chengdu University of Technology in Chengdu of China. Now he works as a Professor in Chongqing University in Chongqing, China. His current research areas are tunnel and underground space, rail transit project, geotechnical engineering and geological engineering. He analyzed the influence of surrounding rock classification on the structural dynamic response to the earthquake action and drew some conclusions. 